\title{
Alkyl-Functionalized Organic Dyes for Efficient Molecular Photovoltaics
}

\author{
Nagatoshi Koumura, ${ }^{* a}$ Zhong-Sheng Wang, ${ }^{a}$ Shogo Mori, ${ }^{b}$ Masanori Miyashita, ${ }^{b}$ Eiji \\ Suzuki, ${ }^{b}$ Kohjiro Hara ${ }^{*} a$ \\ a National Institute of Advanced Industrial Science and Technology, \\ 1-1-1 Higashi, Tsukuba, Ibaraki 305-8565, Japan \\ $b^{b}$ Department of Fine Materials Engineering, Shinshu University, 3-15-1 Tokida, \\ Ueda, Nagano 386-8567, Japan
}

* To whom correspondence should be addressed

Tel: +81-29-861-3474, Fax: +81-29-861-3475, E-mail: n-koumura@aist.go.jp (for N.K.) and k-hara@aist.go.jp (for K.H.)

\section{Supporting Information}

\section{Experimental Section}

General Procedure. ${ }^{1} \mathrm{H}$ NMR spectra were recorded on a Varian VXR-300 (300 MHz). ${ }^{13} \mathrm{C}$ NMR spectra were recorded on a Varian VXR-300 (75 MHz). Chemical shifts are denoted in $\delta$-unit (ppm) relative to $\mathrm{CDCl}_{3}, \mathrm{C}_{2} \mathrm{D}_{2} \mathrm{Cl}_{4}$, THF- $d_{8}$ or DMSO- $d_{6}$. The splitting patterns are designated as follows: s (singlet); d (doublet); t (triplet); q (quartet); m (multiplet) and br (broad). Elemental analyses were measured by a CE Instruments EA1110 automatic elemental analyzer. Column chromatography was performed on silica gel (Kanto, Silica Gel 60N, spherical, $40-50 \mu \mathrm{m}$ ). Most of organic compound was finally purified by the preparative HPLC (YRU-880 detector from SHIMAMURA Tec.) on silica gel (pre-packed column, CPS-HS-221-05 or CPS-223L-1 from KUSANO KAGAKU) The solvents were distilled and dried, if necessary, by standard methods. Reagents and starting materials were used as obtained from Aldrich, Wako, Kanto Chemical, TCI, Merck. Absorption spectra were measured with a SHIMADZU UV-3101PC. The oxidation potential of the dye adsorbed on a $\mathrm{TiO}_{2}$ film was measured by differential pulse voltammetry using a dye-coated $\mathrm{TiO}_{2}$ electrode as the working electrode, a $\mathrm{Pt}$ 


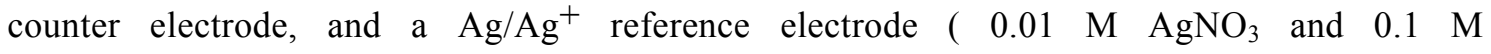
tetrabutylammonium perchlorate in acetonitrile (AN)) in $0.1 \mathrm{M} \mathrm{LiClO}_{4} / \mathrm{AN}$. The measurements were performed with an electrochemical analyzer (ALS, model 610B). The potential was calibrated against the ferrocene redox couple.

\section{Synthesis of Dyes, MK-1 and MK-2}

\section{Scheme 1}
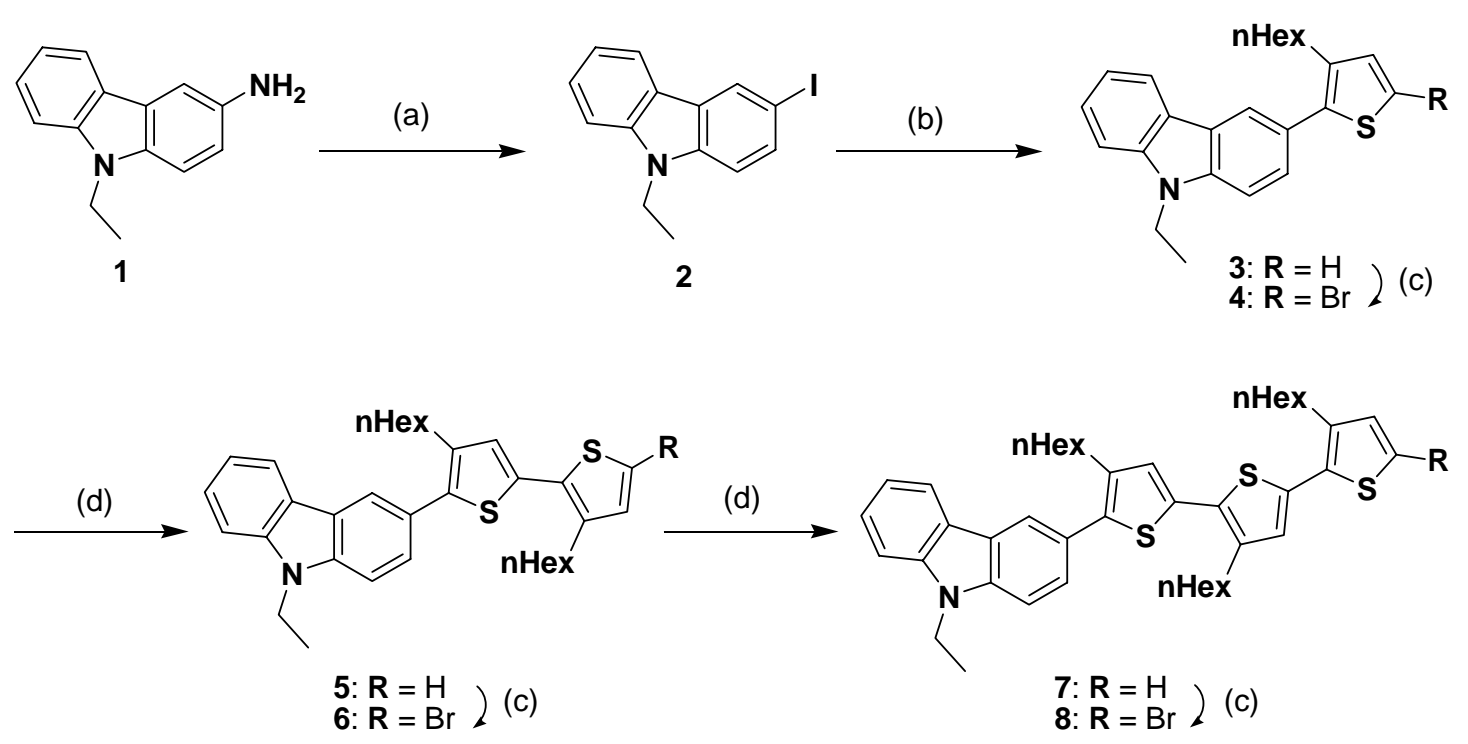

(a) iso-pentyl nitrite, $\mathrm{I}_{2} / \mathrm{THF}$ (b) (i) $\mathrm{Mg}, 2$-bromo-3-n-hexylthiophene /ether (ii) $\mathrm{Ni}(\mathrm{dppp}) \mathrm{Cl}_{2} /$ ether (c) NBS /THF (d) 3-n-hexylthiophene-2-boronic acid neopentyl ester, $\mathrm{Pd}\left(\mathrm{PPh}_{3}\right)_{4}, \mathrm{Na}_{2} \mathrm{CO}_{3}$ aq /DME.

9-Ethyl-3-iodo-9H-carbazole 2. To a solution of 3-amino-9-ethylcarbazole 1 (2.59 g, 11.1 $\mathrm{mmol})$ and iodine $(1.06 \mathrm{~g}, 8.33 \mathrm{mmol})$ in dry THF $(50 \mathrm{~mL})$ was added iso-pentyl nitrite $(2.98 \mathrm{~mL}$, $22.2 \mathrm{mmol})$. The reaction mixture was refluxed for $24 \mathrm{~h}$. After cooling the organic layer was washed with $\mathrm{NaHSO}_{3}$ aq (10\%), NaOHaq (1M), $\mathrm{H}_{2} \mathrm{O}$ and brine, dried with $\mathrm{MgSO}_{4}$, and evaporated under reduced pressure. The crude product was purified by column chromatography (hexane/EtOAc $=100 / 1)$ and successive HPLC on silica gel (hexane/EtOAc $=50 / 1)$ to yield 3-iodo-9-ethylcarbazole $2(1.30 \mathrm{~g}, 4.05 \mathrm{mml}, 36 \%)$ as a white solid; ${ }^{1} \mathrm{H}$ NMR (300 $\left.\mathrm{MHz}, \mathrm{CDCl}_{3}\right)$ $\delta 8.41(1 \mathrm{H}, \mathrm{d}, J=1.6 \mathrm{~Hz}), 8.04(1 \mathrm{H}, \mathrm{br} \mathrm{d}, J=8.1 \mathrm{~Hz}), 7.71(1 \mathrm{H}, \mathrm{dd}, J=8.8,1.6 \mathrm{~Hz}), 7.50(1 \mathrm{H}$, ddd, $J=8.1,7.1,1.1 \mathrm{~Hz}), 7.40(1 \mathrm{H}, \mathrm{br} \mathrm{d}, J=8.1 \mathrm{~Hz}), 7.25(1 \mathrm{H}, \mathrm{ddd}, J=8.1,7.1,1.1 \mathrm{~Hz}), 7.19$ $(1 \mathrm{H}, \mathrm{d}, J=8.8 \mathrm{~Hz}), 4.33(2 \mathrm{H}, \mathrm{q}, J=7.1 \mathrm{~Hz}), 1.42(3 \mathrm{H}, \mathrm{t}, J=7.1 \mathrm{~Hz}),{ }^{13} \mathrm{C}$ NMR $(75 \mathrm{MHz}$, $\left.\mathrm{CDCl}_{3}\right) \delta 139.9,139.0,133.7,129.2,126.3,125.4,121.6,120.5,119.3,110.5,108.6,81.1,37.6$, 13.7. Anal. Calcd for $\mathrm{C}_{14} \mathrm{H}_{12} \mathrm{IN}$ : C, 52.36; H, 3.77; N, 4.36. Found. C, 52.48; H, 3.65; N, 4.20. 
9-Ehtyl-3-(3-n-hexylthiophen-2-yl)-9H-carbazole 3. A Grignard solution was prepared from 2-bromo-3-n-hexylthiophene 2 (903 mg, $3.65 \mathrm{mmol}$ ) and magnesium turning (93 mg, $3.65 \mathrm{mmol}$ ) in anhydrous diethyl ether $(3 \mathrm{~mL})$. The solution was refluxed for $1 \mathrm{~h}$, after cooling $\mathrm{Ni}(\mathrm{dppp}) \mathrm{Cl}_{2}$ (19 $\mathrm{mg}, 0.035 \mathrm{mmol}$ ) was added to the Grignard solution. To this mixture the solution of 9-ethyl-3-iodo-9H-carbazole $(1117 \mathrm{mg}, 3.48 \mathrm{mmol})$ in diethyl ether $(5 \mathrm{~mL})$ was dropwised and the reaction mixture was stirred at room temperature overnight. The mixture was quenched with sat. $\mathrm{NH}_{4} \mathrm{Cl}$ aqueous solution, and extracted with several portions of diethyl ether. The combined organic layer was washed with $\mathrm{H}_{2} \mathrm{O}$ and brine, dried over $\mathrm{MgSO}_{4}$, and evaporated under reduced pressure. The crude product was purified by flash column chromatography (hexane) to afford 930 $\mathrm{mg}$ (2.57 mmmol, 74\%) of 9-ehtyl-3-(3-n-hexylthiophen-2-yl)-9H-carbazole 3 as a colorless oil, ${ }^{1} \mathrm{H}$ NMR $\left(300 \mathrm{MHz}, \mathrm{CDCl}_{3}\right) \delta 8.14(1 \mathrm{H}, \mathrm{d}, J=1.5 \mathrm{~Hz}), 8.10(1 \mathrm{H}, \mathrm{d}, J=7.7 \mathrm{~Hz}), 7.54(1 \mathrm{H}, \mathrm{dd}, J$ $=8.3,1.5 \mathrm{~Hz}), 7.50-7.41(3 \mathrm{H}, \mathrm{m}), 7.27-7.25(1 \mathrm{H}, \mathrm{m}), 7.23(1 \mathrm{H}, \mathrm{d}, J=5.2 \mathrm{~Hz}), 7.01(1 \mathrm{H}, \mathrm{d}, J=$ $5.2 \mathrm{~Hz}), 4.40(2 \mathrm{H}, \mathrm{q}, J=7.2 \mathrm{~Hz}), 2.71(2 \mathrm{H}, \mathrm{dd}, J=8.2,7.4 \mathrm{~Hz}), 1.67-1.63(2 \mathrm{H}, \mathrm{m}), 1.47(3 \mathrm{H}, \mathrm{t}, J$ $=7.2 \mathrm{~Hz}), 1.35-1.26(6 \mathrm{H}, \mathrm{m}), 0.84(3 \mathrm{H}, \mathrm{t}, J=6.8 \mathrm{~Hz}),{ }^{13} \mathrm{C} \mathrm{NMR}\left(75 \mathrm{MHz}, \mathrm{CDCl}_{3}\right) \delta 140.3,139.2$, 138.9, 138.1, 129.3, 127.4, 125.9, 125.3, 123.01, 122.97, 122.8, 121.4, 120.5, 119.0, 108.6, 108.2, 37.6, 31.6, 31.1, 29.2, 28.7, 22.6, 14.0, 13.8. Anal. Calcd for $\mathrm{C}_{24} \mathrm{H}_{27} \mathrm{NS}$ : C, 79.73; H, 7.53; N, 3.87, S, 8.87. Found. C, 79.55; H, 7.44; N, 3.80, S, 9.03.

9-Ehtyl-3-(5-bromo-3-n-hexylthiophen-2-yl)-9H-carbazole 4. To the solution of 9-ehtyl-3-(3-n-hexylthiophen-2-yl)-9H-carbazole 3 (900 mg, $2.49 \mathrm{mmol})$ in THF (15 mL) was added $\mathrm{N}$-bromosuccinimide $(487 \mathrm{mg}, 2.74 \mathrm{mmol})$. The reaction mixture was stirred at room temperature for $30 \mathrm{~min}$, and quenched with $10 \%$ aqueous solution of $\mathrm{Na}_{2} \mathrm{CO}_{3}$ and extracted with EtOAc three times. The combined organic layer was washed with $\mathrm{H}_{2} \mathrm{O}$ and brine, dried over $\mathrm{MgSO}_{4}$, and evaporated under reduced pressure. The crude product was purified by column chromatography (hexane) and successive HPLC on silica gel (hexane/EtOAc $=100 / 1$ ) to obtain bromide 4 (773 mg, $1.76 \mathrm{mml}, 70 \%)$ as a colorless oil, ${ }^{1} \mathrm{H}$ NMR $\left(300 \mathrm{MHz}, \mathrm{CDCl}_{3}\right) \delta 8.09(1 \mathrm{H}, \mathrm{d}$, $J=7.7 \mathrm{~Hz}), 8.08(1 \mathrm{H}, \mathrm{s}), 7.53-7.40(4 \mathrm{H}, \mathrm{m}), 7.25(1 \mathrm{H}, \mathrm{ddd}, J=7.7,6.8,1.1 \mathrm{~Hz}), 6.96(1 \mathrm{H}, \mathrm{s})$, $4.39(2 \mathrm{H}, \mathrm{q}, J=7.1 \mathrm{~Hz}), 2.63(2 \mathrm{H}, \mathrm{t}, J=7.7 \mathrm{~Hz}), 1.65-1.55(2 \mathrm{H}, \mathrm{m}), 1.47(3 \mathrm{H}, \mathrm{t}, J=7.1 \mathrm{~Hz})$, 1.35-1.24 (6H, m), $0.84(3 \mathrm{H}, \mathrm{t}, J=6.8 \mathrm{~Hz}),{ }^{13} \mathrm{C} \mathrm{NMR}\left(75 \mathrm{MHz}, \mathrm{CDCl}_{3}\right) \delta 140.6,140.4,139.4$, 138.8, 131.9, 127.2, 126.0, 124.2, 123.0, 122.7, 121.4, 120.5, 119.1, 109.3, 108.6, 108.4, 37.7, 31.6, 30.9, 29.1, 28.5, 22.6, 14.0, 13.8. Anal. Calcd for $\mathrm{C}_{24} \mathrm{H}_{26}$ BrNS: C, 65.45; H, 5.95; N, 3.18, S, 7.28. Found. C, 65.13; H, 5.94; N, 3.11, S, 7.20.

9-Ethyl-3-(3',4-di-n-hexyl-[2,2']bithiophen-5-yl)-9H-carbazole 5. The mixture of 9-ethyl-3-(5-bromo-3-n-hexylthiophen-2-yl)-9H-carbazole $\quad 4 \quad(366 \quad \mathrm{mg}, \quad 0.83 \quad \mathrm{mml})$, 3-n-hexylthiophene-2-boronic acid neopentyl ester $(349 \mathrm{mg}, 1.25 \mathrm{mmol})$, 
tetrakis(triphenylphosphine)palladium ( $48 \mathrm{mg}, 0.042 \mathrm{mmol}$ ) and $0.5 \mathrm{~mL}$ of $10 \%$ aqueous solution of $\mathrm{Na}_{2} \mathrm{CO}_{3}$ in dimethoxyethane $(20 \mathrm{~mL})$ was refluxed for $24 \mathrm{~h}$. After cooling $\mathrm{H}_{2} \mathrm{O}$ was added, and the reaction mixture was extracted with EtOAc three times. The combined organic layer was washed with $\mathrm{H}_{2} \mathrm{O}$ and brine, dried over $\mathrm{MgSO}_{4}$, and evaporated under reduced pressure. The crude product was purified by column chromatography (hexane $/ \mathrm{CH}_{2} \mathrm{Cl}_{2}=10 / 1$ ) and successive HPLC on silica gel (hexane/EtOAc $=50 / 1)$ to obtain bithiophene $5(349 \mathrm{mg}, 0.66 \mathrm{mml}, 80 \%)$ as a yellow oil, ${ }^{1} \mathrm{H}$ NMR $\left(300 \mathrm{MHz}, \mathrm{CDCl}_{3}\right) \delta 8.17(1 \mathrm{H}, \mathrm{d}, J=1.1 \mathrm{~Hz}), 8.12(1 \mathrm{H}, \mathrm{d}, J=7.7 \mathrm{~Hz})$, $7.56(1 \mathrm{H}, \mathrm{dd}, J=8.4,1.8 \mathrm{~Hz}), 7.53-7.42(3 \mathrm{H}, \mathrm{m}), 7.29-7.23(1 \mathrm{H}, \mathrm{m}), 7.09(1 \mathrm{H}, \mathrm{s}), 7.04(1 \mathrm{H}, \mathrm{d}, J$ $=1.3 \mathrm{~Hz}), 6.80(1 \mathrm{H}, \mathrm{br} \mathrm{s}), 4.40(2 \mathrm{H}, \mathrm{q}, J=7.1 \mathrm{~Hz}), 2.70(2 \mathrm{H}, \mathrm{t}, J=7.8 \mathrm{~Hz}), 2.60(2 \mathrm{H}, \mathrm{t}, J=7.8$ $\mathrm{Hz}), 1.73-1.60(4 \mathrm{H}, \mathrm{m}), 1.48(3 \mathrm{H}, \mathrm{t}, J=7.1 \mathrm{~Hz}), 1.40-1.24(12 \mathrm{H}, \mathrm{m}), 0.91(3 \mathrm{H}, \mathrm{t}, J=6.6 \mathrm{~Hz})$, $0.86(3 \mathrm{H}, \mathrm{t}, J=6.6 \mathrm{~Hz}),{ }^{13} \mathrm{C} \mathrm{NMR}\left(75 \mathrm{MHz}, \mathrm{CDCl}_{3}\right) \delta 144.0,140.3,139.2,138.7,137.9,137.5$, $135.0,127.1,125.9,125.8,125.0,124.5,123.0,122.8,121.1,120.5,119.0,118.4,108.6,108.3$, 37.6, 31.7, 31.6, 31.0, 30.5, 30.3, 29.2, 29.0, 28.8, 22.61, 22.59, 14.1, 14.0, 13.8. Anal. Calcd for $\mathrm{C}_{34} \mathrm{H}_{41} \mathrm{NS}_{2}$ : C, 77.37; H, 7.83; N, 2.65, S, 12.15. Found. C, 77.96; H, 8.22; N, 2.61, S, 11.81 .

\section{9-Ethyl-3-(5'-bromo-3',4-di-n-hexyl-[2,2']bithiophen-5-yl)-9H-carbazole 6. The}

bromination of 9-ethyl-3-(3',4-di-n-hexyl-[2,2']bithiophen-5-yl)-9H-carbazole 5 (300 mg, 0.57 mmol) with $N$-bromosuccinimide $(101 \mathrm{mg}, 0.57 \mathrm{mmol})$ in THF $(10 \mathrm{~mL})$ was carried out in a similar manner to that of 4 . The crude product was purified by column chromatography (hexane/EtOAc $=100 / 1)$ and successive HPLC on silica gel (hexane/EtOAc $=50 / 1)$ to obtain bromide 6 (773 mg, $1.76 \mathrm{mml}, 70 \%)$ as a yellow oil, ${ }^{1} \mathrm{H} \mathrm{NMR}\left(300 \mathrm{MHz}, \mathrm{CDCl}_{3}\right) \delta 8.16(1 \mathrm{H}, \mathrm{d}$, $J=1.1 \mathrm{~Hz}), 8.12(1 \mathrm{H}, \mathrm{d}, J=7.7 \mathrm{~Hz}), 7.57-7.42(4 \mathrm{H}, \mathrm{m}), 7.27(1 \mathrm{H}, \mathrm{ddd}, J=7.7,6.6,1.1 \mathrm{~Hz})$, $7.04(1 \mathrm{H}, \mathrm{s}), 6.89(1 \mathrm{H}, \mathrm{s}), 4.40(2 \mathrm{H}, \mathrm{q}, J=7.1 \mathrm{~Hz}), 2.70(2 \mathrm{H}, \mathrm{t}, J=7.7 \mathrm{~Hz}), 2.57(2 \mathrm{H}, \mathrm{t}, J=7.7$ $\mathrm{Hz}), 1.72-1.58(4 \mathrm{H}, \mathrm{m}), 1.48(3 \mathrm{H}, \mathrm{t}, J=7.1 \mathrm{~Hz}), 1.40-1.24(12 \mathrm{H}, \mathrm{m}), 0.93(3 \mathrm{H}, \mathrm{t}, J=6.6 \mathrm{~Hz})$, $0.87(3 \mathrm{H}, \mathrm{t}, J=6.6 \mathrm{~Hz}),{ }^{13} \mathrm{C}$ NMR $\left(75 \mathrm{MHz}, \mathrm{CDCl}_{3}\right) \delta 142.8,140.3,139.3,138.8,138.4,137.3$, 134.0, 127.1, 126.0, 125.9, 124.7, 123.8, 123.0, 122.7, 121.1, 120.4, 119.0, 108.6, 108.3, 106.9, 37.5, 31.6, 31.6, 30.9, 29.60, 29.58, 29.2, 28.9, 28.8, 22.6, 22.6, 14.1, 14.0, 13.8. Anal. Calcd for $\mathrm{C}_{34} \mathrm{H}_{40} \mathrm{BrNS}_{2}$ : C, 67.31; H, 6.65; N, 2.31, S, 10.57. Found. C, 67.57; H, 6.83; N, 2.33, S, 10.56.

\section{9-Ethyl-3-(3',3',4-tri-n-hexyl-[2,2',5',2'’]terthiophen-5-yl)-9H-carbazole 7. The}

Suzuki-coupling reaction of bromide $6(296 \mathrm{mg}, 0.49 \mathrm{mmol})$ with 3- $n$-hexylthiophene-2-boronic acid neopentyl ester $(273 \mathrm{mg}, 0.98 \mathrm{mmol})$ was carried out in a smilar manner to that of 5 . The crude product was purified by column chromatography (hexane/EtOAc $=50 / 1$ ) and successive HPLC on silica gel (hexane/EtOAc $=50 / 1)$ to obtain terthiophene $7(289 \mathrm{mg}, 0.42 \mathrm{mmol}, 85 \%)$ as a yellow oil, ${ }^{1} \mathrm{H}$ NMR $\left(300 \mathrm{MHz}, \mathrm{CDCl}_{3}\right) \delta 8.17(1 \mathrm{H}, \mathrm{d}, J=1.1 \mathrm{~Hz}), 8.12(1 \mathrm{H}, \mathrm{d}, J=7.7 \mathrm{~Hz})$, $7.56(1 \mathrm{H}, \mathrm{dd}, J=8.4,1.8 \mathrm{~Hz}), 7.53-7.42(3 \mathrm{H}, \mathrm{m}), 7.29-7.23(1 \mathrm{H}, \mathrm{m}), 7.09(1 \mathrm{H}, \mathrm{s}), 7.01(1 \mathrm{H}, \mathrm{s})$, 
$6.98(1 \mathrm{H}, \mathrm{br} \mathrm{s}), 6.89(1 \mathrm{H}, \mathrm{br} \mathrm{s}), 4.40(2 \mathrm{H}, \mathrm{q}, J=7.1 \mathrm{~Hz}), 2.77-2.67(4 \mathrm{H}, \mathrm{m}), 2.62(2 \mathrm{H}, \mathrm{t}, J=7.8$ $\mathrm{Hz}), 1.74-1.61(6 \mathrm{H}, \mathrm{m}), 1.48(3 \mathrm{H}, \mathrm{t}, J=7.1 \mathrm{~Hz}), 1.40-1.24(18 \mathrm{H}, \mathrm{m}), 0.94-0.82(9 \mathrm{H}, \mathrm{m}),{ }^{13} \mathrm{C}$ NMR (75 MHz, $\left.\mathrm{CDCl}_{3}\right) \delta 143.6,140.3,139.9$ 139.3, 138.8, 138.1, 135.8, 135.2, 134.5, 129.5, $127.1,126.9,125.92,125.89,125.89,124.9,123.1,122.8,121.1,120.5,119.8,119.0,108.6$, $108.3,37.6,31.68,31.66,31.64,30.9,30.49,30.48,30.4,29.4,29.24,29.18,29.0,28.8,22.62$, 22.61, 22.59, 14.09, 14.08, 14.05, 13.8. Anal. Calcd for $\mathrm{C}_{44} \mathrm{H}_{55} \mathrm{NS}_{3}$ : C, 76.14; H, 7.99; N, 2.02, S, 13.86. Found. C, 76.70; H, 8.59; N, 1.95, S, 13.42.

\section{9-Ethyl-3-(5'-bromo-3',4-di-n-hexyl-[2,2']bithiophen-5-yl)-9H-carbazole $8 . \quad$ The} bromination of terthiophene $7(360 \mathrm{mg}, 0.52 \mathrm{mmol})$ with $N$-bromosuccinimide $(92 \mathrm{mg}, 0.52$ $\mathrm{mmol})$ in THF $(50 \mathrm{~mL})$ was carried out in a similar manner to that of 4 . The crude product was purified by column chromatography (hexane/EtOAc $=50 / 1$ ) and successive HPLC on silica gel (hexane/EtOAc $=50 / 1)$ to obtain bromide $8(398 \mathrm{mg}, 0.52 \mathrm{mml}, 99 \%)$ as a yellow oil, ${ }^{1} \mathrm{H} \mathrm{NMR}$ $\left(300 \mathrm{MHz}, \mathrm{CDCl}_{3}\right) \delta 8.18(1 \mathrm{H}, \mathrm{d}, J=1.6 \mathrm{~Hz}), 8.13(1 \mathrm{H}, \mathrm{d}, J=7.7 \mathrm{~Hz}), 7.56(1 \mathrm{H}, \mathrm{dd}, J=8.5,1.6$ $\mathrm{Hz}), 7.54-7.43(3 \mathrm{H}, \mathrm{m}), 7.30-7.24(1 \mathrm{H}, \mathrm{m}), 7.10(1 \mathrm{H}, \mathrm{s}), 7.02(1 \mathrm{H}, \mathrm{s}), 6.84(1 \mathrm{H}, \mathrm{s}), 4.40(2 \mathrm{H}, \mathrm{q}, J$ $=7.1 \mathrm{~Hz}), 2.74-2.56(4 \mathrm{H}, \mathrm{m}), 2.59(2 \mathrm{H}, \mathrm{t}, J=7.7 \mathrm{~Hz}), 1.74-1.58(6 \mathrm{H}, \mathrm{m}), 1.48(3 \mathrm{H}, \mathrm{t}, J=7.1 \mathrm{~Hz})$, 1.44-1.28 (18H, m), 0.94-0.82 (9H, m), ${ }^{13} \mathrm{C}$ NMR (75 MHz, $\left.\mathrm{CDCl}_{3}\right) \delta 142.4,140.5,140.3,139.3$, 138.9, 138.4, 135.8, 135.6, 134.2, 128.4, 127.1, 126.4, 126.1, 125.9, 125.8, 124.8, 123.1, 122.8 , $121.1,120.5,119.1,108.6,108.37,108.35,37.6,31.64,31.62,30.9,30.5,29.6,29.5,29.4,29.21$, $29.19,28.90,28.88,28.82,22.6,22.6,22.6,14.08,14.08,14.05,13.8$. Anal. Calcd for $\mathrm{C}_{44} \mathrm{H}_{54} \mathrm{BrNS}_{3}$ : C, 68.37; H, 7.04; N, 1.81, S, 12.44. Found. C, 68.79; H, 7.29; N, 1.96, S, 12.22.

\section{Scheme 2}

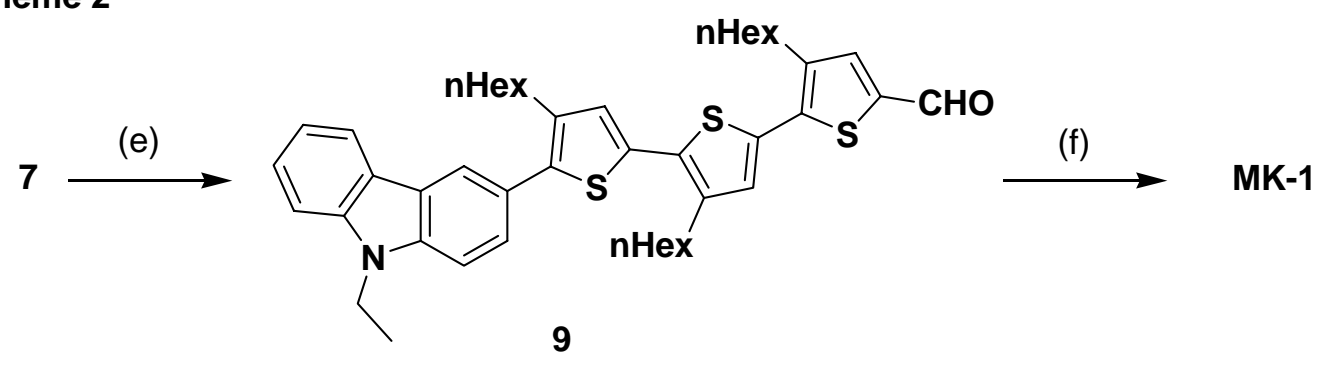

(e) $\mathrm{POCl}_{3}-\mathrm{DMF} / \mathrm{DMF}$ (f) cyanoacetic acid, piperidine / $\mathrm{AcCN}$

\section{5',-(9-Ethyl-9H-carbazol-3-yl)-3,4',4'’-tri-n-hexyl-[2,2',5',2'’]terthiophenyl-5-carbaldehy-}

de 9. To a cold solution of terthiophene $7(224 \mathrm{mg}, 0.32 \mathrm{mmol})$ in dry DMF $(1 \mathrm{~mL})$ at $0{ }^{\circ} \mathrm{C}$ was added a Vilsmeier reagent, which was prepared with $0.1 \mathrm{~mL}$ of $\mathrm{POCl}_{3}$ in DMF $(0.5 \mathrm{~mL})$. The mixture was stirred at $70{ }^{\circ} \mathrm{C}$ for $4 \mathrm{~h}$, and quenched with $10 \%$ aqueous solution of $\mathrm{NaOAc}(30$ $\mathrm{mL}$ ) after cooling, and extracted with EtOAc three times. The combined organic layer was 
washed with $\mathrm{H}_{2} \mathrm{O}$ and brine, dried over $\mathrm{MgSO}_{4}$, and evaporated under reduced pressure. The crude product was purified by column chromatography (hexane/EtOAc $=15 / 1)$ and successive HPLC on silica gel (hexane/EtOAc $=15 / 1)$ to obtain aldehyde $9(195 \mathrm{mg}, 0.27 \mathrm{mml}, 84 \%)$ as an orange oil, ${ }^{1} \mathrm{H}$ NMR $\left(300 \mathrm{MHz}, \mathrm{CDCl}_{3}\right) \delta 10.02(1 \mathrm{H}, \mathrm{s}), 8.17(1 \mathrm{H}, \mathrm{d}, J=1.4 \mathrm{~Hz}), 8.12(1 \mathrm{H}, \mathrm{d}, J$ $=7.7 \mathrm{~Hz}), 7.55(1 \mathrm{H}, \mathrm{dd}, J=8.5,1.7 \mathrm{~Hz}), 7.53-7.42(3 \mathrm{H}, \mathrm{m}), 7.29-7.23(1 \mathrm{H}, \mathrm{m}), 7.14(1 \mathrm{H}, \mathrm{s})$, $7.05(2 \mathrm{H}, \mathrm{br} \mathrm{s}), 4.40(2 \mathrm{H}, \mathrm{q}, J=7.1 \mathrm{~Hz}), 2.95(2 \mathrm{H}, \mathrm{t}, J=7.7 \mathrm{~Hz}), 2.82(2 \mathrm{H}, \mathrm{t}, J=7.7 \mathrm{~Hz}), 2.71$ $(2 \mathrm{H}, \mathrm{t}, J=7.7 \mathrm{~Hz}), 1.74-1.61(6 \mathrm{H}, \mathrm{m}), 1.48(3 \mathrm{H}, \mathrm{t}, J=7.1 \mathrm{~Hz}), 1.44-1.24(18 \mathrm{H}, \mathrm{m}), 0.94-0.83$ $(9 \mathrm{H}, \mathrm{m}),{ }^{13} \mathrm{C} \mathrm{NMR}\left(75 \mathrm{MHz}, \mathrm{CDCl}_{3}\right) \delta 181.4,153.3,145.3,142.9,140.3,139.3,139.2,139.0$, 137.6, 135.9, 133.6, 128.0, 127.8, 127.0, 126.6, 126.3, 126.0, 124.6, 123.0, 122.7, 121.0, 120.4, 119.0, 108.6, 108.4, 37.6, 31.60, 31.58, 31.5, 31.3, 30.9, 30.1, 29.9, 29.2, 29.1, 28.9, 28.8, 28.4, 22.54, 22.54, 22.49, 14.02, 14.00, 14.00, 13.8. Anal. Calcd for $\mathrm{C}_{45} \mathrm{H}_{55} \mathrm{NOS}_{3}$ : C, 74.85; H, 7.68; N, 1.94, S, 13.32. Found. C, 74.57; H, 7.90; N, 1.94, S, 12.87.

\section{2-Cyano-3-[5',-(9-Ethyl-9H-carbazol-3-yl)-3,4',4',-tri-n-hexyl-[2,2',5',2'’]terthiophenyl-5-}

yl]acrylic acid MK-1. A mixture of aldehyde $9(181 \mathrm{mg}, 0.25 \mathrm{mmol})$ with cyanoacetic acid (32 $\mathrm{mg}, 0.38 \mathrm{mmol})$ in dry acetonitrile $(2 \mathrm{~mL})$ was refluxed in the presence of piperidine $(0.5 \mathrm{~mL})$ for $4 \mathrm{~h}$. After cooling the mixture was diluted with dichloromethane, and the organic layer was washed with $\mathrm{H}_{2} \mathrm{O}$ and brine, dried over $\mathrm{Na}_{2} \mathrm{SO}_{4}$, and evaporated under reduced pressure. The crude product was purified by column chromatography $\left(\mathrm{CHCl}_{3} \rightarrow \mathrm{CHCl}_{3} / \mathrm{EtOAc}=1 / 1\right)$ to obtain a dye MK-1 (137 mg, $0.13 \mathrm{mmol}, 69 \%)$ as dark-red solids, ${ }^{1} \mathrm{H}$ NMR (300 MHz, DMSO-d $\left.d_{6}\right) \delta 8.23-8.16(3 \mathrm{H}, \mathrm{m}), 7.65(1 \mathrm{H}, \mathrm{d}, J=8.8 \mathrm{~Hz}), 7.62(1 \mathrm{H}, \mathrm{d}, J=8.5 \mathrm{~Hz}), 7.51-7.44(2 \mathrm{H}$, m), $7.32(1 \mathrm{H}, \mathrm{s}), 7.25(1 \mathrm{H}, \mathrm{s}), 7.23(1 \mathrm{H}, \mathrm{s}), 7.19(1 \mathrm{H}, \mathrm{d}, J=7.4 \mathrm{~Hz}), 4.45(2 \mathrm{H}, \mathrm{q}, J=7.1 \mathrm{~Hz})$, 2.80-2.70 (4H, m), $2.64(2 \mathrm{H}, \mathrm{t}, J=7.7 \mathrm{~Hz}), 1.68-1.52(6 \mathrm{H}, \mathrm{m}), 1.32(3 \mathrm{H}, \mathrm{t}, J=7.7 \mathrm{~Hz}), 1.38-1.14$ $(18 \mathrm{H}, \mathrm{m}), 0.83(3 \mathrm{H}+3 \mathrm{H}, \mathrm{t}, J=6.6 \mathrm{~Hz}), 0.75(3 \mathrm{H}, \mathrm{t}, J=6.6 \mathrm{~Hz}),{ }^{13} \mathrm{C}$ NMR $\left(75 \mathrm{MHz}, \mathrm{DMSO}-d_{6}\right) \delta$ 164.1, 154.1, 143.3, 142.0, 141.4, 140.2, 139.2, 139.0, 138.8, 136.9, 132.9, 129.2, 127.7, 127.5, 127.2, 126.8, 126.4, 124.0, 122.6, 122.1, 120.79, 120.75, 119.2, 117.8, 109.55, 109.49, 79.4, 37.3, $31.2,31.12,31.10,30.7,30.2,29.8,29.5,28.8,28.7,28.5,28.4,28.3,22.23,22.19,22.18,14.1$, 14.1, 14.03, 13.9. Anal. Calcd for $\mathrm{C}_{48} \mathrm{H}_{56} \mathrm{~N}_{2} \mathrm{O}_{2} \mathrm{~S}_{3}: \mathrm{C}, 73.05 ; \mathrm{H}, 7.15 ; \mathrm{N}, 3.55, \mathrm{~S}, 12.19$. Found. C, $72.89 ; \mathrm{H}, 7.46 ; \mathrm{N}, 3.49, \mathrm{~S}, 11.65$. 


\section{Scheme 3}

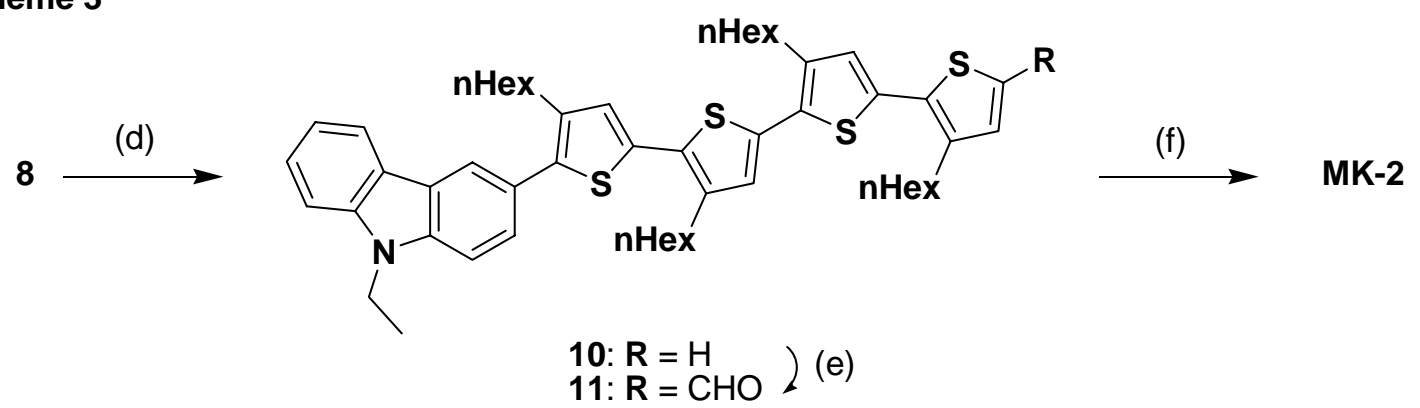

\section{9-Ethyl-3-(3',3',,3'”,4-tetra-n-hexyl-[2,2',5',2',5',,2',']quaterthiophen-5-yl)-9H-carbazo-}

le 10. The Suzuki-coupling reaction of bromide $8(279 \mathrm{mg}, 0.36 \mathrm{mmol})$ with 3-n-hexylthiophene-2-boronic acid neopentyl ester $(202 \mathrm{mg}, 0.72 \mathrm{mmol})$ was carried out in a smilar manner to that of 5 . The crude product was purified by column chromatography (hexane/EtOAc $=50 / 1)$ and successive HPLC on silica gel (hexane/EtOAc $=50 / 1)$ to obtain quaterthiophene 10 (286 mg, $0.33 \mathrm{mmol}, 92 \%)$ as an orange oil, ${ }^{1} \mathrm{H}$ NMR $\left(300 \mathrm{MHz}, \mathrm{CDCl}_{3}\right) \delta$ $8.19(1 \mathrm{H}, \mathrm{s}), 8.13(1 \mathrm{H}, \mathrm{d}, J=7.7 \mathrm{~Hz}), 7.57(1 \mathrm{H}, \mathrm{d}, J=8.2 \mathrm{~Hz}), 7.54-7.43(3 \mathrm{H}, \mathrm{m}), 7.30-7.25(1 \mathrm{H}$, m), $7.12(1 \mathrm{H}, \mathrm{s}), 7.04(1 \mathrm{H}, \mathrm{s}), 7.00(1 \mathrm{H}, \mathrm{br} \mathrm{s}), 6.99(1 \mathrm{H}, \mathrm{s}), 6.92(1 \mathrm{H}, \mathrm{br} \mathrm{s}), 4.41(2 \mathrm{H}, \mathrm{q}, J=7.1$ $\mathrm{Hz}), 2.83-2.69(6 \mathrm{H}, \mathrm{m}), 2.64(2 \mathrm{H}, \mathrm{t}, J=7.7 \mathrm{~Hz}), 1.78-1.62(8 \mathrm{H}, \mathrm{m}), 1.49(3 \mathrm{H}, \mathrm{t}, J=7.1 \mathrm{~Hz})$, 1.48-1.26 (24H, m), 0.95-0.85 (12H, m), ${ }^{13} \mathrm{C}$ NMR (75 MHz, $\left.\mathrm{CDCl}_{3}\right) \delta 143.6,140.3,140.2$, 139.6 139.3, 138.9, 138.2, 135.6, 135.3, 134.4, 133.8, 130.8, 129.1, 128.3, 127.2, 127.1, 126.1, $125.99,125.95,124.9,123.1,122.8,121.2,120.5,120.0,119.1,108.6,108.4,37.7,31.68,31.68$, $31.68,31.65,31.0,30.55,30.50,30.46,30.4,29.5,29.3,29.24,29.24,29.19,29.0,28.8,22.63$, 22.63, 22.63, 22.60, 14.09, 14.09, 14.09, 14.05, 13.9. Anal. Calcd for $\mathrm{C}_{54} \mathrm{H}_{69} \mathrm{NS}_{4}: \mathrm{C}, 75.38 ; \mathrm{H}$, 8.08; N, 1.63, S, 14.91. Found. C, 75.90; H, 8.19; N, 1.69, S, 14.45.

5,',-(9-Ethyl-9H-carbazol-3-yl)-3',3',,3',',4-tetra-n-hexyl-[2,2',5',2,',5', ,2,']quaterthiophenyl-5-carbaldehyde 11. To a cold solution of quaterthiophene $10(270 \mathrm{mg}, 0.31 \mathrm{mmol})$ in dry DMF $(1 \mathrm{~mL})$ at $0{ }^{\circ} \mathrm{C}$ was added a Vilsmeier reagent, which was prepared with $0.1 \mathrm{~mL}$ of $\mathrm{POCl}_{3}$ in DMF $(0.5 \mathrm{~mL})$. The mixture was stirred at $70{ }^{\circ} \mathrm{C}$ for $4 \mathrm{~h}$, and quenched with $10 \%$ aqueous solution of NaOAc $(30 \mathrm{~mL})$ after cooling, and extracted with EtOAc three times. The combined organic layer was washed with $\mathrm{H}_{2} \mathrm{O}$ and brine, dried over $\mathrm{MgSO}_{4}$, and evaporated under reduced pressure. The crude product was purified by column chromatography (hexane/EtOAc $=20 / 1)$ and successive HPLC on silica gel (hexane/EtOAc $=15 / 1)$ to obtain aldehyde $11(225 \mathrm{mg}, 0.25 \mathrm{mml}$, $81 \%)$ as a dark-orange oil, ${ }^{1} \mathrm{H}$ NMR $\left(300 \mathrm{MHz}, \mathrm{CDCl}_{3}\right) \delta 10.03(1 \mathrm{H}, \mathrm{s}), 8.18(1 \mathrm{H}, \mathrm{d}, J=1.4 \mathrm{~Hz})$, $8.13(1 \mathrm{H}, \mathrm{d}, J=7.7 \mathrm{~Hz}), 7.56(1 \mathrm{H}, \mathrm{dd}, J=8.5,1.7 \mathrm{~Hz}), 7.54-7.43(3 \mathrm{H}, \mathrm{m}), 7.30-7.24(1 \mathrm{H}, \mathrm{m})$, $7.13(1 \mathrm{H}, \mathrm{s}), 7.06(1 \mathrm{H}, \mathrm{s}), 7.04(1 \mathrm{H}, \mathrm{s}), 7.01(1 \mathrm{H}, \mathrm{s}), 4.40(2 \mathrm{H}, \mathrm{q}, J=7.1 \mathrm{~Hz}), 2.96(2 \mathrm{H}, \mathrm{t}, J=7.7$ $\mathrm{Hz}), 2.84(2 \mathrm{H}, \mathrm{t}, \mathrm{J}=7.7 \mathrm{~Hz}), 2.80(2 \mathrm{H}, \mathrm{t}, J=7.7 \mathrm{~Hz}), 2.72(2 \mathrm{H}, \mathrm{t}, J=7.7 \mathrm{~Hz}), 1.77-1.64(8 \mathrm{H}, \mathrm{m})$, 
$1.48(3 \mathrm{H}, \mathrm{t}, J=7.1 \mathrm{~Hz}), 1.44-1.26(24 \mathrm{H}, \mathrm{m}), 0.96-0.84(12 \mathrm{H}, \mathrm{m}),{ }^{13} \mathrm{C} \mathrm{NMR}\left(75 \mathrm{MHz}, \mathrm{CDCl}_{3}\right) \delta$ $181.5,153.3,145.1,142.4,141.0,140.3,139.3,138.9,138.6,136.14,136.13,136.12,134.1$, $129.2,128.7,128.3,128.0,127.1,126.2,126.1,126.0,124.8,123.1,122.8,121.1,120.5,119.1$, 108.6, 108.4, 37.6, 31.65, 31.65, 31.63, 31.5, 31.4, 30.9, 30.3, 30.2, 29.8, 29.6, 29.23, 29.23, $29.17,29.0,28.8,28.5,22.60,22.58,22.58,22.53,14.09,14.05,14.03,14.03,13.8$. Anal. Calcd for $\mathrm{C}_{55} \mathrm{H}_{69} \mathrm{NOS}_{4}: \mathrm{C}, 74.36 ; \mathrm{H}, 7.83 ; \mathrm{N}, 1.58, \mathrm{~S}, 14.44$. Found. C, 74.53; H, 8.20; N, 1.59, S, 14.16 .

2-Cyano-3-[5','-(9-Ethyl-9H-carbazol-3-yl)-3',3',,3', ',4-tetra-n-hexyl-[2,2',5',2,',5,',2,']quaterthiophenyl -5-yl]acrylic acid MK-2. A mixture of aldehyde 11 (211 mg, $0.24 \mathrm{mmol})$ with cyanoacetic acid $(40 \mathrm{mg}, 0.48 \mathrm{mmol})$ in a mixed solvent of dry acetonitrile $(5 \mathrm{~mL})$ and dry toluene $(2 \mathrm{~mL})$ was refluxed in the presence of piperidine $(1 \mathrm{~mL})$ for $4 \mathrm{~h}$. After cooling the mixture was diluted with dichloromethane, and the organic layer was washed with $\mathrm{H}_{2} \mathrm{O}$ and brine, dried over $\mathrm{Na}_{2} \mathrm{SO}_{4}$, and evaporated under reduced pressure. The crude product was purified by column chromatography $\left(\mathrm{CHCl}_{3} \rightarrow \mathrm{EtOAc} \rightarrow \mathrm{CHCl}_{3} /\right.$ ethanol $=10 / 1 \rightarrow \mathrm{CHCl}_{3} /$ ethanol $\left.=1 / 1\right)$ and subsequent recrystallization from $\mathrm{CHCl}_{3}$-ethanol to obtain a dye MK-2 $(216 \mathrm{mg}, 0.23 \mathrm{mmol}$, 95\%) as dark-red solids, ${ }^{1} \mathrm{H}$ NMR $\left(300 \mathrm{MHz}, \mathrm{THF}-\mathrm{d}_{8}\right) \delta 8.39(1 \mathrm{H}, \mathrm{s}), 8.16(1 \mathrm{H}, \mathrm{s}), 8.08(1 \mathrm{H}, \mathrm{d}, J$ $=7.7 \mathrm{~Hz}), 7.56-7.39(4 \mathrm{H}, \mathrm{m}), 7.17(1 \mathrm{H}, \mathrm{d}, J=7.7 \mathrm{~Hz}), 7.14(1 \mathrm{H}, \mathrm{s}), 7.05(2 \mathrm{H}, \mathrm{s}), 6.59(1 \mathrm{H}, \mathrm{s})$, $4.42(2 \mathrm{H}, \mathrm{q}, J=6.9 \mathrm{~Hz}), 2.86-2.66(8 \mathrm{H}, \mathrm{m}), 1.71-1.60(8 \mathrm{H}, \mathrm{m}), 1.40(3 \mathrm{H}, \mathrm{t}, J=6.9 \mathrm{~Hz})$, 1.40-1.25 (24H, m), 0.95-0.82 (12H, m), ${ }^{13} \mathrm{C}$ NMR (75 MHz, THF-d $d_{8} \delta 168.5,153.2,142.7$, $142.2,141.8,141.5,141.4,140.4,139.6,139.6,136.8,136.2$, 135.1, 131.6, 130.7, 129.6, 129.5, $127.8,127.0,126.9,126.7,125.7,124.1,123.8,121.7,121.1,119.8,118.9,109.57,109.48,76.2$, $38.132 .8,32.73$, 32.66, 32.6, 32.3, 31.8, 31.3, 31.2, 30.8, 30.6, 30.5, 30.3, 30.2, 30.1, 29.9, 29.6, 23.55, 23.53, 23.47, 23.47, 14.6, 14.53, 14.50, 14.4, 14.1. Anal. Calcd for $\mathrm{C}_{58} \mathrm{H}_{70} \mathrm{~N}_{2} \mathrm{O}_{2} \mathrm{~S}_{4}: \mathrm{C}$, 72.91; H, 7.38; N, 2.93, S, 13.42. Found. C, 73.19; H, 7.42; N, 2.98, S, 13.42.

\section{Synthesis of the dye, MK-3}

\section{Scheme 4}

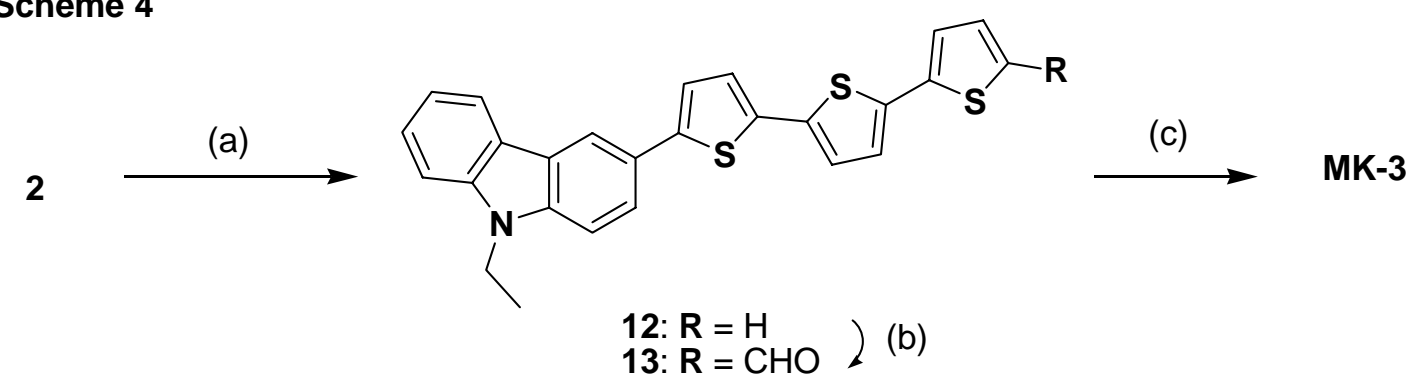


(a) $\left[2,2^{\prime}, 5^{\prime}, 2^{\prime}\right.$ ' $]$ terthiophene-5-boronic acid neopentyl ester, $\mathrm{Pd}\left(\mathrm{PPh}_{3}\right)_{4}, \mathrm{Na}_{2} \mathrm{CO}_{3}$ aq /DME (b) $\mathrm{POCl}$ - $\mathrm{DMF}$ $/ \mathrm{DMF}$ (f) cyanoacetic acid, piperidine $/ \mathrm{CHCl}_{3}-\mathrm{AcCN}$

9-Ethyl-3-([2,2',5',2'’]terthiophen-5-yl)-9H-carbazole 12. The Suzuki-coupling reaction of iodide 2 (86 mg, $0.27 \mathrm{mmol}$ ) with terthiophene-2-boronic acid neopentyl ester (150 mg, 0.40 $\mathrm{mmol})$ and $\mathrm{Pd}\left(\mathrm{PPh}_{3}\right)_{4}(15 \mathrm{mg}, 0.013 \mathrm{mmol})$ in DME $(3 \mathrm{~mL})$ was carried out in the presence of 0.2 $\mathrm{mL}$ of aqueous $\mathrm{Na}_{2} \mathrm{CO}_{3}$ at $60{ }^{\circ} \mathrm{C}$ for $10 \mathrm{~h}$. After cooling the reaction mixture was diluted with chloroform and the organic layer was washed with $\mathrm{H}_{2} \mathrm{O}$ and brine, and dried over $\mathrm{MgSO}_{4}$. The solvent was evaporated under the reduced pressure. The crude product was purified by column chromatography (hexane/dichloromethane $=2 / 1$ ) and successive HPLC on silica gel (hexane/EtOAc $=10 / 1)$ to obtain terthiophene $12(66 \mathrm{mg}, 0.15 \mathrm{mmol}, 56 \%)$ as yellow solids, ${ }^{1} \mathrm{H}$ NMR $\left(300 \mathrm{MHz}_{\mathrm{CDCl}}\right) \delta 8.32(1 \mathrm{H}, \mathrm{d}, J=1.7 \mathrm{~Hz}), 8.15(1 \mathrm{H}, \mathrm{d}, J=7.7 \mathrm{~Hz}), 7.73(1 \mathrm{H}, \mathrm{dd}, J=$ $8.5,1.7 \mathrm{~Hz}), 7.50(1 \mathrm{H}, \mathrm{ddd}, J=8.2,7.1,1.1 \mathrm{~Hz})), 7.43(1 \mathrm{H}, \mathrm{d}, J=8.2 \mathrm{~Hz}), 7.40(1 \mathrm{H}, \mathrm{d}, J=8.5$ $\mathrm{Hz}), 7.30-7.17(5 \mathrm{H}, \mathrm{m}), 7.11(2 \mathrm{H}, \mathrm{dd}, J=4.1 \mathrm{~Hz}), 7.04(1 \mathrm{H}, \mathrm{dd}, J=5.2,3.6 \mathrm{~Hz}), 4.38(2 \mathrm{H}, \mathrm{q}, J=$ $7.1 \mathrm{~Hz}), 1.46(3 \mathrm{H}, \mathrm{t}, J=7.1 \mathrm{~Hz}),{ }^{13} \mathrm{C} \mathrm{NMR}\left(75 \mathrm{MHz}, \mathrm{CDCl}_{3}\right) \delta 144.9,140.4,139.6137 .3,136.6$, $135.7,135.0,127.9,126.1,125.2,125.1,124.6,124.38,124.36,123.9,123.7,123.6,123.4,122.8$, 122.6, 120.6, 119.1, 117.6, 108.8, 108.7, 37.7, 13.8. Anal. Calcd for $\mathrm{C}_{26} \mathrm{H}_{19} \mathrm{NS}_{3}$ : C, 70.71; H, 4.34; N, 3.17, S, 21.78. Found. C, 70.54; H, 4.31; N, 3.15, S, 21.66.

5'’-(9-Ethyl-9H-carbazol-3-yl)-[2,2',5',2'’]terthiophenyl-5-carbaldehyde 13. To a cold solution of terthiophene $12(66 \mathrm{mg}, 0.15 \mathrm{mmol})$ in dry DMF $(1 \mathrm{~mL})$ at $0{ }^{\circ} \mathrm{C}$ was added a Vilsmeier reagent, which was prepared with $0.1 \mathrm{~mL}$ of $\mathrm{POCl}_{3}$ in $\mathrm{DMF}(0.5 \mathrm{~mL})$. The mixture was stirred at $70{ }^{\circ} \mathrm{C}$ for $4 \mathrm{~h}$, and quenched with $10 \%$ aqueous solution of $\mathrm{NaOAc}(30 \mathrm{~mL})$ after cooling, and extracted with dichloromethane three times. The combined organic layer was washed with $\mathrm{H}_{2} \mathrm{O}$ and brine, dried over $\mathrm{MgSO}_{4}$, and evaporated under reduced pressure. The crude product was purified by column chromatography (hexane/EtOAc = 3/1) and recrystallization from hexane-chloroform to obtain aldehyde 13 (50 $\mathrm{mg}, 0.11 \mathrm{mml}, 71 \%$ ) as orange needles, ${ }^{1} \mathrm{H}$ NMR $\left(300 \mathrm{MHz}, \mathrm{C}_{2} \mathrm{D}_{2} \mathrm{Cl}_{4}\right) \delta 9.82(1 \mathrm{H}, \mathrm{s}), 8.30(1 \mathrm{H}$, br s), $8.14(1 \mathrm{H}$, br d, $J=$ $7.7 \mathrm{~Hz}), 7.73(1 \mathrm{H}$, br d, $J=8.3 \mathrm{~Hz}), 7.69(1 \mathrm{H}, \mathrm{d}, J=3.8 \mathrm{~Hz})), 7.54-7.42(3 \mathrm{H}, \mathrm{m}), 7.32-7.17(6 \mathrm{H}$, m), $4.36\left(2 \mathrm{H}\right.$, br s), $1.45(3 \mathrm{H}, \mathrm{t}, J=7.1 \mathrm{~Hz}),{ }^{13} \mathrm{C} \mathrm{NMR}\left(75 \mathrm{MHz}, \mathrm{C}_{2} \mathrm{D}_{2} \mathrm{Cl}_{4}\right) \delta 182.5,146.8,145.6$, $141.0,140.2$, 139.4, 137.8, 134.0, 133.7, 127.0, 126.1, 125.5, 124.6, 124.1, 124.0, 123.8, 123.0, $122.7,122.3,120.4,119.1,117.4,108.9$, 108.7, 37.6, 13.8. Anal. Calcd for $\mathrm{C}_{27} \mathrm{H}_{19} \mathrm{NOS}_{3}$ : C, 69.05; H, 4.08, N, 2.98, S, 20.48. Found. C, 68.89; H, 4.09; N, 2.99, S, 20.32. 
mmol) in dry acetonitrile $(2 \mathrm{~mL})$ and chloroform $(2 \mathrm{~mL})$ was refluxed in the presence of piperidine $(0.5 \mathrm{~mL})$ for $4 \mathrm{~h}$. After cooling the precipitates was filtrated, and the crude product was purified by recrystalization from chloroform-ethanol to obtain a dye MK-3 (40 mg, 0.075 mmol, $87 \%)$ as dark-red solids, ${ }^{1} \mathrm{H}$ NMR $\left(300 \mathrm{MHz}\right.$, DMSO- $\left.d_{6}\right) \delta 8.50(1 \mathrm{H}, \mathrm{s}), 8.25(1 \mathrm{H}, \mathrm{d}, J=$ $7.7 \mathrm{~Hz}), 8.12(1 \mathrm{H}, \mathrm{s}), 7.78(1 \mathrm{H}, \mathrm{dd}, J=8.5,1.7 \mathrm{~Hz}), 7.72(1 \mathrm{H}, \mathrm{d}, J=3.8 \mathrm{~Hz}), 7.66(1 \mathrm{H}, \mathrm{d}, J=8.8$ $\mathrm{Hz}), 7.62(1 \mathrm{H}, \mathrm{d}, J=8.5 \mathrm{~Hz}), 7.53(1 \mathrm{H}, \mathrm{d}, J=3.8 \mathrm{~Hz}), 7.50-7.45(3 \mathrm{H}, \mathrm{m}), 7.44(1 \mathrm{H}, \mathrm{d}, J=3.8$ $\mathrm{Hz}), 7.37(1 \mathrm{H}, \mathrm{d}, J=3.8 \mathrm{~Hz}), 7.23(1 \mathrm{H}, \mathrm{t}, J=7.4 \mathrm{~Hz}), 4.45(2 \mathrm{H}, \mathrm{q}, J=7.1 \mathrm{~Hz}), 1.32(3 \mathrm{H}, \mathrm{t}, J=$ $7.1 \mathrm{~Hz}),{ }^{13} \mathrm{C}$ NMR $\left(75 \mathrm{MHz}\right.$, DMSO-d $\left.d_{6}\right) \delta 163.2,144.9,141.4,140.9,140.3,139.5,137.6,137.3$, 135.9, 133.9, 133.6, 127.1, 126.4, 126.2, 125.0, 124.7, 124.4, 123.8, 123.7, 122.9, 122.3, 121.0, 119.3, 119.1, 117.5, 110.0, 109.6, 37.3, 13.9. Anal. Calcd for $\mathrm{C}_{30} \mathrm{H}_{20} \mathrm{~N}_{2} \mathrm{O}_{2} \mathrm{~S}_{3}$ : C, 67.14; H, 3.76; N, 5.22, S, 17.92. Found. C, 66.76; H, 3.51; N, 5.06, S, 17.92.

\section{Preparation of Dye-sensitized $\mathrm{TiO}_{2}$ Electrodes}

Nanocrystalline $\mathrm{TiO}_{2}$ photoelectrodes were prepared by a screen printing technique. $\mathrm{TiO}_{2}$ nanoparticles and an organic $\mathrm{TiO}_{2}$ paste for screen printing were prepared by methods reported in a previous paper (Wang, Z.-S.; Kawauchi, H.; Kashima, T.; Arakawa, H. Coord. Chem. Rev. 2004, 248, 1381-1389). The $\mathrm{TiO}_{2}$ paste consisted of $\mathrm{TiO}_{2}$ nanoparticles (ca. $20 \mathrm{~nm}$ ), ethyl cellulose as a binder, and $\alpha$-terpineol as a solvent. $\mathrm{The}^{\mathrm{TiO}}{ }_{2}$ paste, which is commercial available (SOLARONIX, T), was also used. The $\mathrm{TiO}_{2}$ paste was printed on a glass substrate coated with transparent conducting oxide (TCO, F-doped $\mathrm{SnO}_{2}$ ) and subsequently sintered at $500{ }^{\circ} \mathrm{C}$ in air for $1 \mathrm{~h}$. The thickness of the $\mathrm{TiO}_{2}$ thin films, measured with an Alpha-Step 300 profiler (TENCOR INSTRUMENTS), was ca. $6.5 \mu \mathrm{m}$. We also used thicker $\mathrm{TiO}_{2}$ film electrode (ca. $30 \mu \mathrm{m}$ ) including a scattering layer, which consisted of large $\mathrm{TiO}_{2}$ particles (av. $100 \mathrm{~nm}$ ). The MK dyes were dissolved at a concentration of $0.3 \mathrm{mM}$ in toluene (KANTO CHEMICAL). The $\mathrm{TiO}_{2}$ films were immersed in the dye solutions and then kept at $25{ }^{\circ} \mathrm{C}$ for more than $12 \mathrm{~h}$ to allow the dye to adsorb to the $\mathrm{TiO}_{2}$ surface.

\section{Photovoltaic Measurements of the Solar Cells.}

The each photovoltaic cell, consisted of a dye-sensitized $\mathrm{TiO}_{2}$ electrode, a Pt counter electrode sputtered (ca. $200 \mathrm{~nm})$ onto TCO-coated glass plate, a film spacer $(30 \mu \mathrm{m}$ thickness) and an 
organic electrolyte, was prepared. The apparent surface area of the $\mathrm{TiO}_{2}$ film electrode was ca. $0.25 \mathrm{~cm}^{2}$. The electrolyte was $0.6 \mathrm{M} \mathrm{1,2-dimethyl-3-n-propylimidazolium} \mathrm{iodide} \mathrm{(DMPImI)}+0.1$ $\mathrm{M}$ LiI $+0.05 \mathrm{M} \mathrm{I}_{2}+0.5 \mathrm{M}$ 4-tert-butylpyridine (TBP) in AN. Reagent-grade LiI (WAKO CHEMICAL) and $\mathrm{I}_{2}$ (WAKO) were used for the electrolyte. DMPImI was purchased from TOMIYAMA PURE CHEMICAL INDUSTRIES Ltd.

The photovoltaic performance of the solar cells was measured with a source meter (ADVANTEST, R6246). We employed an AM 1.5G solar simulator (WACOM, WXS-80C-3 and YAMASHITA DENSO Co., YSS-150A) as the light source. The incident light intensity was calibrated by using a standard solar cell composed of a crystalline silicon solar cell and an IR-cut off filter (SCHOTT, KG-5), giving the photoresponse range of amorphous silicon solar cell (produced and calibrated by Japan Quality Assurance Organization). We used an aperture mask $\left(0.2354 \mathrm{~cm}^{2}\right)$ attached onto the top of the cells in the photovoltaic measurements. Action spectra of the monochromatic incident photon-to-current conversion efficiency (IPCE) of the solar cell were measured with a CEP-99W system (BUNKOH-KEIKI Co., Ltd.).

All data (Jsc, Voc, FF, and $\eta$ ) are described in Table S1, and IV and Dark current spectra of DSSCs besed on dyes, MK-1, MK-2 an MK-3 are shown in Figure S1. The each absorbed photon to current conversion efficiency (APCE) value of DSSCs with dyes, MK-1, MK-2 and MK-3 was calculated from the value of IPCE and absorbance at $500 \mathrm{~nm}$ based on the following equation, respectively, dipicted in Table S2. Figure S2 shows action spectra of DSSCs based on dyes, MK-1, MK-2 and MK-3. Each condition of the measurements are displayed in each caption, respectively.

$$
\begin{aligned}
& L H E=1-10^{-A} \\
& A P C E=\frac{I P C E}{L H E}
\end{aligned}
$$

LHE: Light Harvesting Efficiency

A: absorbace 


\begin{tabular}{|l|c|c|c|c|}
\hline Dye & $J_{s c} / \mathrm{mA} \mathrm{cm}^{-2}$ & $V_{o c} / \mathrm{V}$ & $F F$ & $\eta(\%)$ \\
\hline N719 $^{\mathrm{a}}$ & 10.1 & 0.79 & 0.77 & 6.1 \\
& 10.5 & 0.79 & 0.76 & 6.3 \\
\hline MK-1 $^{\text {a }}$ & 10.9 & 0.72 & 0.71 & 5.6 \\
& 11.1 & 0.71 & 0.71 & 5.6 \\
\hline MK-2 $^{\text {a }}$ & 12.4 & 0.72 & 0.71 & 6.3 \\
& 12.3 & 0.72 & 0.71 & 6.3 \\
\hline MK-3 $^{\text {a }}$ & 10.2 & 0.64 & 0.72 & 4.7 \\
& 10.8 & 0.63 & 0.71 & 4.8 \\
\hline MK-2 $^{\text {b }}$ & 14.0 & 0.74 & 0.74 & 7.7 \\
\hline N719 $^{\text {c }}$ & 16.1 & 0.76 & 0.74 & 9.1 \\
\hline
\end{tabular}

Table S1. Photovoltaic performance of the DSSCs based on MK dyes. Incident light: AM 1.5G $\left(100 \mathrm{~mW} \mathrm{~cm}^{-2}\right)$ with a mask $\left(0.2354 \mathrm{~cm}^{2}\right)$ and without an anti-reflection film. Electrolyte: $0.6 \mathrm{M}$ DMPImI $+0.1 \mathrm{M} \mathrm{LiI}+0.05 \mathrm{M} \mathrm{I}_{2}+0.5 \mathrm{M}$ TBP in acetonitrile. $\mathrm{TiO}_{2}$ electrode: $\mathrm{ca} 0.25 \mathrm{~cm}^{2}$ and film thickness ${ }^{\mathrm{a}} 6.5 \mu \mathrm{m},{ }^{\mathrm{b}} 30 \mu \mathrm{m}$ and ${ }^{\mathrm{c}} 16 \mu \mathrm{m}$.

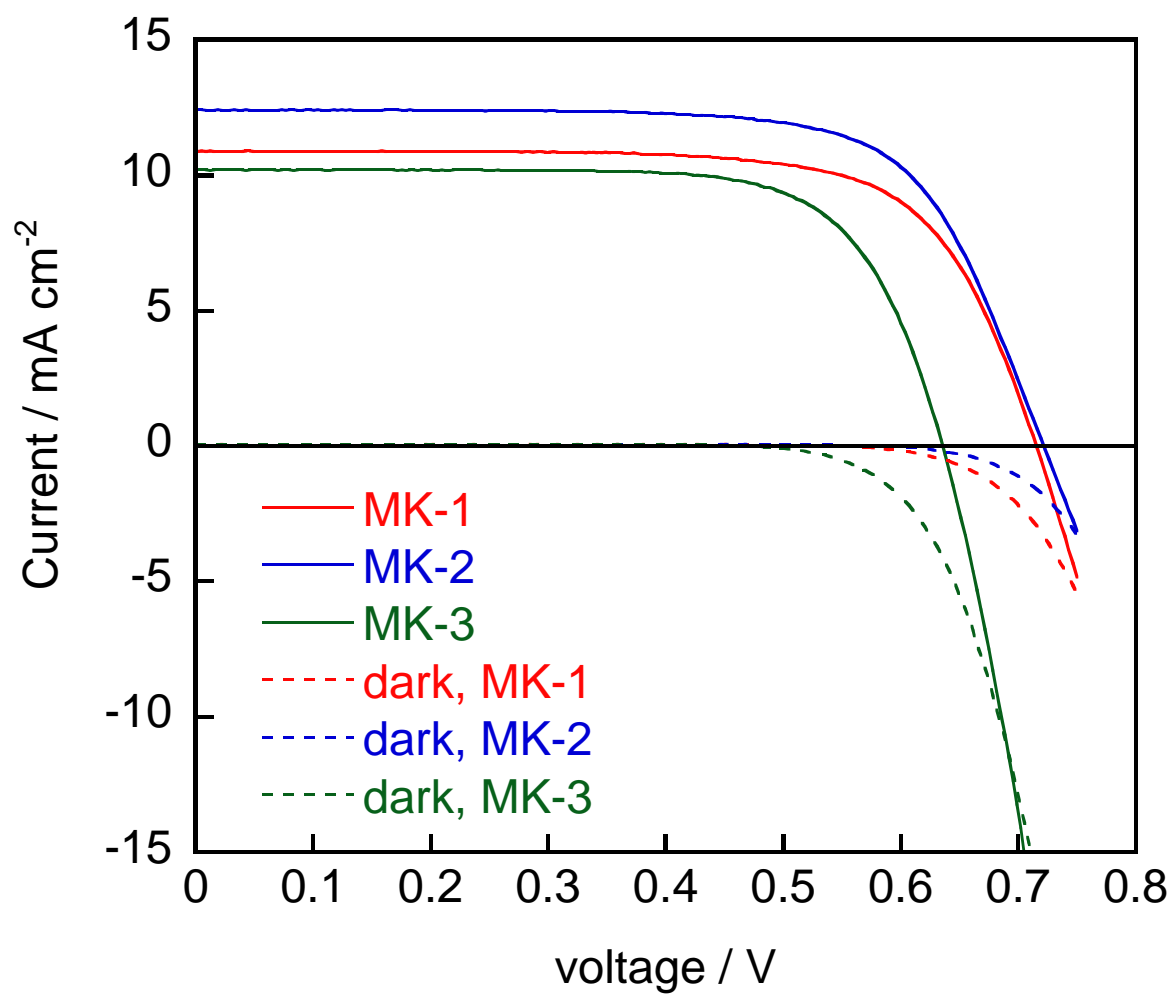

Figure S1. IV and Dark curves of DSSCs based on MK-1, MK-2 and MK-3. Incident light: AM 
$1.5 \mathrm{G}\left(100 \mathrm{~mW} \mathrm{~cm}{ }^{-2}\right)$ with a mask $\left(0.2354 \mathrm{~cm}^{2}\right)$ and without an anti-reflection film. Electrolyte: 0.6 M DMPImI $+0.1 \mathrm{M} \mathrm{LiI}+0.05 \mathrm{M} \mathrm{I}_{2}+0.5 \mathrm{M}$ TBP in acetonitrile. $\mathrm{TiO}_{2}$ electrode: ca $0.25 \mathrm{~cm}^{2}$ and film thickness $6.5 \mu \mathrm{m}$.

\begin{tabular}{|l|c|c|c|}
\hline & IPCE & LHE & APCE \\
\hline MK-1 & 0.67 & 0.94 & 0.71 \\
\hline MK-2 & 0.68 & 0.95 & 0.72 \\
\hline MK-3 & 0.59 & 0.96 & 0.61 \\
\hline
\end{tabular}

Table S2. The value of APCEs of DSSCs bease on dyes, MK-1, MK-2 and MK-3, respectively.

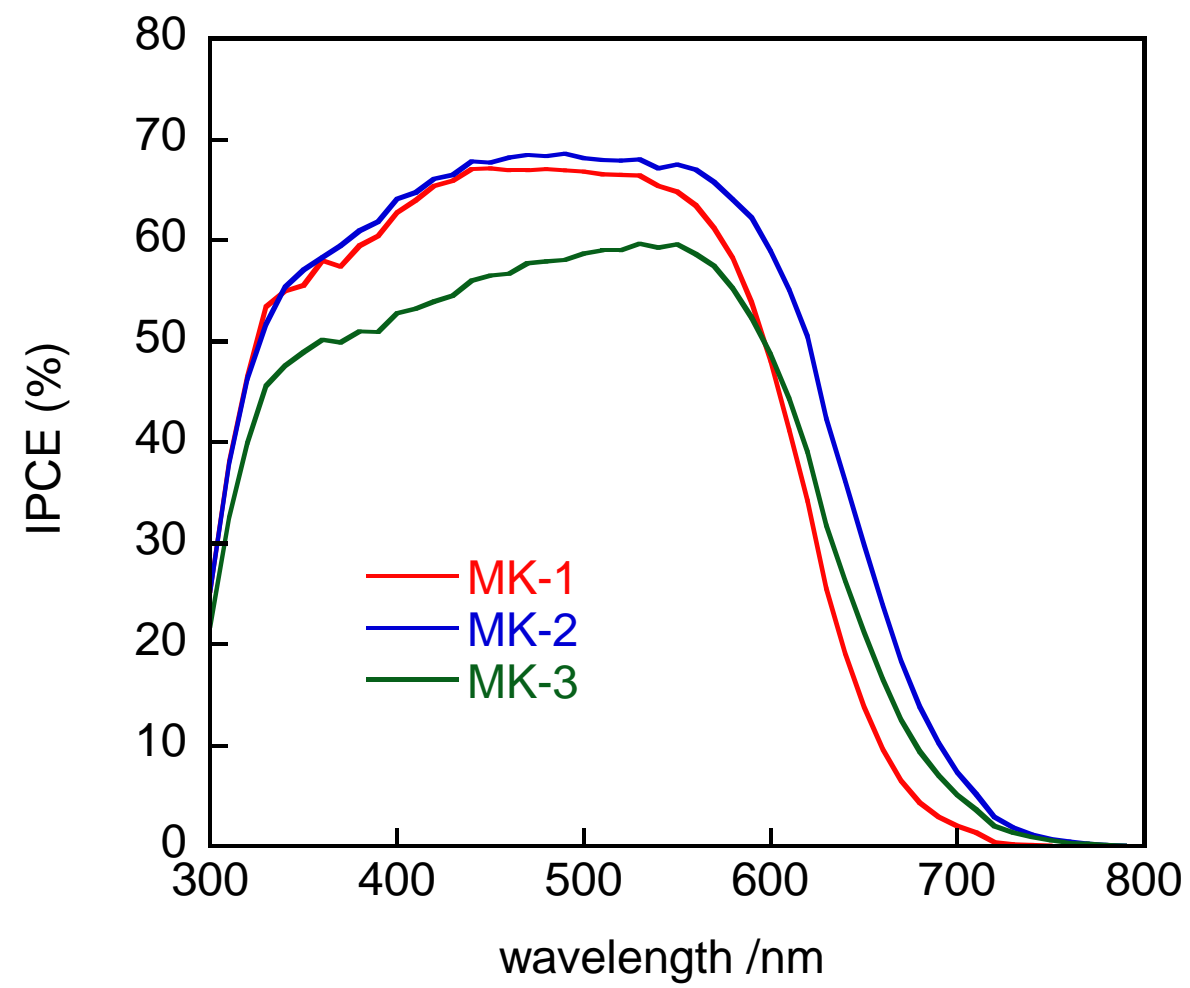

Figure S2. Action spectra of monochromatic incident photon-to-current conversion efficiency (IPCE) for DSSCs based on dyes, MK-1, MK-2 and MK-3. These spectra were measured with a mask $\left(0.2354 \mathrm{~cm}^{2}\right)$ and without an anti-reflection film. Electrolyte: $0.6 \mathrm{M} \mathrm{DMPImI}+0.1 \mathrm{M} \mathrm{LiI}+$ $0.05 \mathrm{M} \mathrm{I}_{2}+0.5 \mathrm{M}$ TBP in acetonitrile. $\mathrm{TiO}_{2}$ electrode: ca $0.25 \mathrm{~cm}^{2}$ and film thickness $6.5 \mu \mathrm{m}$. 


\section{Transient Photovoltage Measurements}

Electron lifetimes in the DSSCs were obtained by stepped light-induced transient measurements of photovoltage. For the measurements, $\mathrm{TiO}_{2}$ electrodes were prepared from Solaronix- $\mathrm{T}$ by sintering at $550{ }^{\circ} \mathrm{C}$ for $30 \mathrm{~min}$ in air. Experimental procedure of the measurements is described in detail elsewhere (Nakade et al. Langmuir 2005, 21, 10803-10807). In short, DSSCs were irradiated by a diode laser (Coherent, Lablaser, $\lambda=635 \mathrm{~nm}$ ) and the decay of open circuit voltage, caused by step-wise decrease of a small fraction of the laser intensity, was measured. The measurement was repeated with various initial laser intensities, giving different electron density in the DSSCs. Electron lifetime $(\tau)$ was obtained by fitting an exponential function, $\exp (-t / \tau)$, to the voltage decay. The electron density used to plot Fig. 3 was estimated by the charge extraction method introduced by Peter and co-workers (Duffy et al. Electrochemistry Communications 2000, 2, 658-662). Our experimental setup is described in a paper (Nakade et al. Journal of Physical Chemistry B, 2005, 109, 3480-3487). In short, irradiated laser light was turned off simultaneously with the switch from open circuit to short circuit conditions. Then, the induced transient current was recorded, and then the amount of the charges in the DSSC at open circuit conditions was obtained by numerical integration of the current transient. The control of the laser intensity and circuit conditions was performed by LabVIEW with a DAQ card (National Instruments). 